\section{The Role of Pharmacy Benefit Managers in Formulary Design: Service Providers or Fiduciaries?}

To the Editor:

Drug benefit plan sponsors often contract with pharmacy benefit managers (PBMs) to assist them in the design and management of their plans. PBMs exercise discretion over a key component of the benefit plan-the design of a preferred drug list, or national formulary, that the plan sponsor uses as a starting point for its own local formulary. Generally, such elements as copayments and "prior authorization" requirements are part of the plan design rather than the formulary design and, hence, are discretionary acts of the plan sponsor. But, even on occasion, these elements are built into national formularies by the PBM. The basic point is that PBMs exercise some discretion when they assist sponsors in the overall design of drug benefit plans.

PBMs have come under intense attack in the past few years for not acting in the best interests of their clients. Clients are charging that PBMs are designing formularies that are not cost effective. They say that PBMs are "rebate chasers" that design-in higher cost drugs just to capture a rebate percentage. Clients argue that if PBMs were subject to full disclosure under fiduciary laws, formulary designs would be more cost effective. Yet, the benefits of subjecting PBMs to full disclosure provisions of fiduciary laws are problematic. Proving breach of fiduciary duty requires outcome as well as cost data, and PBM fiduciary laws being proposed today are silent on the need for outcome data.

Managers of employee benefits plans are held to a higher standard of business ethics and accountability than others in the business world. A key determinant of this elevated status is whether or not an entity exercises discretionary control with material consequences over the plan. PBMs say that a plan sponsor makes all key decisions regarding the design of the benefits plan and, in particular, the design of its formulary.

However, PBMs do not present their clients with a blank lookup table and ask them to populate each of 60 to 80 formulary classes from the list of drugs approved for safety and efficacy by a pharmacy and therapeutics committee. They do acknowledge "ownership" of their own formularies that serve as a starting point in the design process. Also, PBMs do not simply present plan sponsors with the entire set of manufacturer rebate schedules and ask them to make final choices based on that information. They have developed proprietary financial modeling software that they use in assisting clients to make formulary choices. Quoting from a PBM white paper on formulary design ${ }^{1}$.

Express Scripts' plan sponsors often adopt Express Scriptsdeveloped formularies as their own or use them as the foundation for their own custom formularies.

Throughout the process, Express Scripts provides consultative services, including financial modeling, to the plan sponsors and the plan sponsor ultimately decides what plan to offer.

Sponsors are indeed free to choose whatever they want, but
PBMs use discretion in choosing the estimated, and actual, rebate implications of those choices. The basis for certain market-share rebates is complex, and the gross and net rebates attributable to any single plan may be dependent on formulary choices of other plans under contract with any PBM. The choice of parameters used in formulary financial models is a discretionary act of PBMs that has material consequences. These parameters are likely based on an assumed central tendency of their client base to adopt formularies similar to the ones used at the start of the design process-one of the national formularies "owned" by the PBM.

I have demonstrated, using simple game theory, that marketshare rebates would not work, that is, "move markets," if PBMs started the formulary design process with a blank slate. ${ }^{2}$ Plan sponsors would be facing a game-like situation akin to the "prisoner dilemma," where the optimal strategy would be to choose to keep a therapeutic class open (the "confess-confess" strategy). As I stated in my paper "The Formulary Game," closed formularies do not move markets, but closely aligned ones do. This is achieved when plan sponsors use national formularies as a starting point for further customization.

The goal of formulary management-design and compliance-is to improve the safety and cost-effectiveness of prescription drug usage while taking into account the value plan members place on freedom of choice. The paragraphs above focused on formulary design at the individual therapeuticclass level. Now, we turn our attention to an overall design decision. Designers must choose the number of therapeutic classes in a formulary. We call that characteristic of a formulary its "granularity." Typically, the national formularies of large PBMs have 60 to 80 different therapeutic classes. In order to provide comprehensive care, they have to make sure that all nonformulary drugs have at least 1 formulary drug that is therapeutically equivalent. A therapeutic class can be viewed as a market - a place where choices are made from a set of substitutable goods. A formulary is a group of separate markets. One can reduce the competition for inclusion in the formulary by creating very narrowly defined therapeutic classes.

For example, instead of 1 broad class for calcium channel blockers, there might be 3 more refined classes of calcium channel blockers-benzothiazepines, dihydropyridines, and phenylalkylamines. A particular brand-name drug might find itself designated as nonformulary when the formulary has only a single large class for calcium channel blockers because it is pitted against a more cost-effective generic drug that is therapeutically equivalent. Even though both drugs are calcium channel blockers and therapeutically equivalent, the brand-name drug is in the subclass, dihydropyridines, while the generic is in the subclass, benzothiazepine. If a drug formulary were more highly refined with 3 separate classes for calcium channel blockers, there would be no competition between the brand drug and a lower-cost, therapeutically equivalent 
generic. A highly refined formulary limits the possibility of generic substitution and therapeutic interchange. As such, a highly refined formulary can drive up the costs of a drug benefit considerably. The granularity of a formulary is not a scientific absolute, but a discretionary act with material consequences.

Fiduciary laws can be viewed as 2 interrelated mandates. There is generally a vague behavioral mandate that fiduciaries must act in the best interest of clients. To insure compliance, there are disclosure mandates that fiduciaries must report all sources of income associated with their management activity. The idea is that sources of income other than fees from clients create the potential for a conflict of interest. We now turn our attention to how full disclosure might resolve efficiency issues in practice. At the outset, it is important to recognize that there are 2 aspects to formulary management-design and compliance. Full disclosure of rebates may be useful in uncovering areas of inefficient formulary design by PBMs. Only detailed audits of prescription transactions can uncover PBM-mandated switching by community and mail-order pharmacies that are not in compliance with the formulary.

The key point we wish to make is that evidence that a higherpriced drug is preferred to a lower-priced therapeutic equivalent is not sufficient to prove breach of fiduciary duty. First, one must prove that the designation was a discretionary act of a PBM and not a discretionary act of a client. If it can be determined that the designation deviated from the national formulary and was initiated by a client, then a PBM cannot be held accountable. Second, a client's interest is best served by costeffective formulary design, not simply a design that minimizes costs. Full-disclosure laws only specify rebate data so there is a question of how useful this data is alone without related outcome data. To illustrate what data are needed to determine breach of fiduciary duty, consider the following statins chosen by PBMs to be in their national formulary: ${ }^{3}$ Express Scripts, Inc: (lovastatin, Lipitor, Crestor, Zocor); Caremark Rx, Inc.: (Pravachol, Lipitor); and Aetna, Inc.: (lovastatin, Lescol, Zocor). Are any of these choices a breach of fiduciary duty? What kinds of data would you need to prove, or disprove, such an allegation?

A graph published recently in the Journal of Managed Care Pharmacy by Morrison and Glassberg is exactly what is needed to begin to determine the cost-effectiveness of the above choices. ${ }^{4}$ Based on an extensive review of pharmacoeconomic studies of statins, they drew a scatter plot-their Figure 1-of the percentage reduction in low-density lipoprotein cholesterol against nominal drug costs (excluding rebates) for 7 statins of various dosages. By connecting the lowest-cost drug for any given level of effectiveness, they derived an "efficient frontier" curve. Even without rebate data, this graph makes clear that a cost-effective national formulary must contain at least 2 statins: 1 for patients with low risk of coronary heart disease and 1 for patients with a higher risk. Excluding rebates, the graph indicates that for low-risk patients, generic lovastatin would be a more cost-effective choice than Lescol or Pravachol. For higher-risk patients, Crestor would be a more cost-effective choice than Lipitor, which, in turn, would be a more costeffective choice than Zocor.

To complete the analysis, rebates received by plan sponsors must be factored into the Morrison and Glassberg graph. But, plan sponsors already know firsthand what level of rebates they receive so full-disclosure laws would be redundant. Full-disclosure laws are really about forcing PBMs to reveal gross rebates received from manufacturers and rebate-retention rates. Gross rebate receipt data are useful to determine questions of equity rather than efficiency as measured by cost-effectiveness.

It seems that proponents of full-disclosure laws are using the rhetoric of efficiency to mask concerns about equity. It is far easier to build the case against PBMs by claiming that they are not acting responsibly than to claim that they are doing their best for clients but are just getting paid too much. There may be some value in limited disclosure laws, especially for resolving issues of equity. Unfortunately, the full-disclosure laws being drafted today are both too broad and too narrow at the same time. They require disclosure of all rebates, when studies have shown that the bulk of rebates and, hence, potential for conflict of interest, are concentrated in about 10 formulary classes. Why not simplify the data requirements by limiting rebate data requests to only the top 10 rebate-generating drugs? At the same time, add requirements that PBMs disclose the pharmacoeconomic studies they use to support their preferences in those top rebate-generating therapeutic classes.

Lawrence W. Abrams, PhD Economist, Nu-Retail 1734 Villa St., \#6, Mountain View, CA 94041 labrams@nu-retail.com

\section{DISCLOSURES}

The author discloses no conflict of interest or any potential bias regarding this letter.

\section{REFERENCES}

1. Express Scripts, Inc. White Paper: Formulary Management at Express Scripts. Available at: http://www.express-scripts.com/other/company/formulary_development_whitepaper.pdf. Accessed June 6, 2004.

2. Abrams LW. The formulary game. Available at: http://www.nu-retail.com/ formulary-game-website.pdf. Accessed June 6, 2004

3. Express Scripts national preferred formulary. Available at: https://member. express-scripts.com/formulary/OpenFormulary.do?portal= member\&formulary Id=393 Accessed June 7, 2004. Caremark preferred drug list. Available at: https://www.caremark.com/portal/asset/preferred_drug_list.pdf . Accessed June 6, 2004. Aetna medication formulary. Available at: http:www.aetna.com/formulary/ heart_2004.html\#X0704. Accessed June 6, 2004.

4. Morrison A, Glassberg H. Determinants of the cost-effectiveness of statins. J Manag Care Pharm. 2003;9(6):544-51. 